\title{
Os ditados populares no ensino de espanhol como língua estrangeira: estrutura e processos semânticos
}

\author{
Laura Pissani \\ Pontifícia Universidade Católica do Rio de Janeiro
}

\begin{abstract}
Resumo
Este artigo tem por objetivo discutir o ensino de ditados espanhóis em aulas de espanhol como língua estrangeira. Para isso, serão analisados os processos semânticos e estruturas linguísticas de dez ditados da língua espanhola achados em manuais de ensino. Para tal análise, lançamos mão da teoria cognitiva, especialmente da teoria da metáfora e metonímia conceptuais iniciada por Lakoff e Johnson (1980) que propõe que as metáforas estão não só na língua, mas também no pensamento, ou seja, elas formam parte do nosso sistema cognitivo e refletem nosso modo de pensar, agir e nos comportar. Portanto, os ditados não são somente uma forma de conhecer a língua, mas também a cultura.
\end{abstract}

Palavras-chave: metáfora, ditados, ensino de espanhol

\begin{abstract}
The main objective of this research is to discuss how Spanish sayings are taught in a class of Spanish as a foreign language. For this purpose, we analyze semantic processes and linguistic structures of a corpus of ten Spanish sayings found in language learning books. In order to analyze the corpus, we use the cognitive theory, especially the conceptual metaphor and metonymy theory formulated by Lakoff and Johnson (1980), which postulates that metaphor is not only in language but also in thought. That is, metaphors are part of our cognitive system and reflect our way of thinking, acting and behaving. Therefore, sayings are a way to learn not only the language but also the culture.
\end{abstract}

Keywords: metaphor, proverbs, Spanish teaching

\section{INTRODUÇÃO}

Os ditados são frases completas e independentes, parêmias populares caraterizadas por ter temática genérica, sentido idiomático e expressar um pensamento produto da experiência de forma dinâmica. Eles foram herdados de forma oral de geração em geração com o objetivo principal de transmitir uma mensagem produto da sabedoria popular. (Casares, 1992; Zuluaga, 1980; Martínez, 1989; Alonso, 1978; Pérez, 1993, 1997; Corpas, 1996; Almela, P.; Sevilla M., 2000; Sevilla, 1988, 2012; Pérez, 2008; Penadés, 2006, 2012).

Os processos semânticos envolvidos na criação dos ditados podem ser facilmente decifrados pelos falantes nativos inseridos na cultura onde o ditado nasceu. Porém, um falante não nativo, alheio à cultura e à língua do ditado dificilmente poderá 
decodificar a linguagem figurada na língua alvo, o que dificultará a interpretação adequada do significado dos ditados.

Um dos principais processos semânticos presentes nos ditados populares espanhóis é a metáfora; portanto, neste artigo será feita uma análise dos processos metafóricos em dez ditados populares espanhóis e de como o nosso esquema cognitivo se manifesta na linguagem através destas estruturas. Tal análise será feita de acordo com a Teoria da Metáfora Conceptual.

\section{FUNDAMENTOS TEÓRICOS: A TEORIA DA METÁFORA CONCEPTUAL}

A Linguística Cognitiva é um movimento que concebe a linguagem como um fenômeno integrado dentro das capacidades humanas. Ela parte da premissa de que a faculdade da linguagem não pode ser analisada de maneira autônoma. É necessário recorrer às reflexões entre a linguagem e outras faculdades cognitivas como a memória, a percepção, a categorização, as quais permitem aportar explicações ao problema de como funciona a linguagem (Cuenca e Hilferty, 1999).

A Linguística Cognitiva é uma corrente que agrupa uma série de teorias orientadas ao estudo da linguagem com diferentes propósitos, porém, regidas sob os mesmos pressupostos sobre o funcionamento da língua. Algumas teorias que estão dentro dessa linha são a Teoria da Metáfora e Metonímia Conceptuais, a Gramática de Construções, a Gramática Cognitiva, a Teoria dos espaços mentais e a integração conceptual e a Semântica de frames.

Neste trabalho, nosso foco será a Teoria da Metáfora e Metonímia Conceptuais postulada por George Lakoff e Mark Johnson no livro Metaphors we live by publicado em 1980 pela Universidade de Chicago (Estados Unidos).

Nesta teoria, se postula que as metáforas não são unicamente recursos estilísticos limitados ao campo da literatura; pelo contrario, elas impregnam a linguagem ordinária e são parte da vida diária. As metáforas não estão somente na língua, elas são parte do nosso sistema conceptual, que dirige o nosso modo de pensar e atuar; portanto, nosso sistema conceptual é altamente metafórico, o qual é evidenciado nas atividades cotidianas e na forma de perceber o mundo.

A metáfora conceptual é um fenômeno cognitivo no qual um determinado campo semântico é representado em termos de outro; isto é, o conhecimento de um campo semântico mais concreto e perto da experiência física é utilizado para explicar 
outro campo mais abstrato que resulta difícil de ser descrito. O primeiro campo é denominado DOMÍNIO FONTE, enquanto o segundo campo é denominado DOMÍNIO ALVO.

$\mathrm{Na}$ teoria da metáfora, é importante diferenciar entre os conceitos metáfora conceptual e expressões metafóricas (ou metáforas linguísticas). As metáforas conceptuais são esquemas abstratos do pensamento que se manifestam na língua através das expressões metafóricas; portanto, uma metáfora conceptual pode motivar muitas expressões metafóricas, as quais podem mudar em cada língua, embora a metáfora conceptual seja a mesma. A metáfora conceptual será apresentada no formato: DOMÍNIO ALVO É DOMÍNIO FONTE.

Por exemplo, a metáfora conceptual na qual se expressa o tempo em termos de dinheiro seria formulada: O TEMPO É DINHEIRO. Nessa concepção são usados elementos relacionados ao campo semântico do dinheiro, com o qual se tem contato diariamente, para explicar o tempo, que é um conceito abstrato. Esta metáfora conceptual motiva expressões metafóricas como 'perder o tempo', 'poupar tempo', 'aproveitar o tempo', etc.

Uma metáfora conceptual possui um conjunto de associações sistemáticas denominadas projeções, que são dadas entre elementos do domínio fonte e o domínio alvo; também, as associações entre os elementos de ambos os domínios são denominadas correspondências ontológicas; por exemplo, a pessoa que possui o dinheiro seria equivalente à pessoa que dispõe do tempo.

As metáforas não são arbitrárias, elas têm a sua motivação principalmente na base experiencial ou na percepção de uma semelhança entre os dois domínios. A base experiencial radica na coocorrência de dois domínios sistematicamente nas interações com o entorno. Por exemplo, o domínio do calor é utilizado para estruturar o domínio do afeto; assim, se diz que uma pessoa é fria quando não demonstra seus sentimentos e existem outras expressões que derivam dessa metáfora como 'dar calorosos aplausos' ou 'se comportar com frialdade'. Possivelmente, esta correlação entre o afeto e o calor seja pela atuação do calor nas experiências vitais; assim, quando uma mãe abraça seu bebe, o faz para transmitir calor e ao mesmo tempo afeto.

A segunda motivação é a percepção de uma semelhança entre os domínios. Este parecido pode ser real ou percebido. Por exemplo, o objeto com forma de rato que é chamado, precisamente, de mouse (rato) é um parecido real; ou pode ser um parecido percebido como no caso de diversas caraterísticas que são associadas com certos animais e nem sempre são adequadas; como no caso de algumas culturas nas quais os 
leões são percebidos como animais corajosos, porém, não é um dado cientificamente comprovado, pelo contrário segundo alguns documentais, os leões parecem ser muito preguiçosos.

As metáforas conceptuais são caraterizadas por serem um fenômeno cognitivo, dentro e fora da linguagem, suas principais caraterísticas são (1) A capacidade de expressar o abstrato em termos do concreto e a corporificação, que descreve o fato de poder utilizar a informação de um domínio concreto e perceptual para estruturar outro domínio abstrato e imperceptível. Por exemplo, é possível explicar conceitos abstratos como O BEM e O MAL em termos de outros domínios perceptíveis aos sentidos humanos como A CLARIDADE e A ESCURIDÃO, respectivamente; isto é visível em expressões metafóricas como 'ver as coisas com claridade', 'ter um panorama escuro', etc.

(2) A hierarquia. As metáforas não são fenômenos isolados, muitas delas constituem casos específicos de metáforas mais gerais, herdam sua estrutura e formam parte de uma hierarquia, como no caso da metáfora conceptual geral AS ATIVIDADES DE LONGA DURAÇÃO COM OBJETIVOS SÃO VIAGENS da qual se derivam metáforas conceptuais mais especificas como A VIDA É UMA VIAGEM.

(3) As associações entre os domínios são parciais. Por exemplo, na metáfora conceptual COMPREENDER É VER (e.g. 'Não vejo por que') nem todas as caraterísticas do domínio fonte são mapeadas no domínio alvo, somente as pertinentes. Tal fenômeno é conhecido como a hipótese da invariabilidade. A parcialidade das projeções se explica através da teoria da seleção das propriedades que sugere que o domínio fonte pode ser caraterizado em termos de propriedades prototípicas e só algumas delas são projetadas no domínio alvo.

Desse modo, a metáfora conceptual COMPREENDER É VER apresenta associações como 'analisar é olhar com mais detalhe', 'não pensar logicamente é estar cego pela paixão', porém, aspectos da visão como os órgãos que participam ou as propriedades físicas da luz não são pertinentes para o mapeamento.

O domínio da visão serve para mostrar o caráter de multiplicidade das metáforas conceptuais, onde um mesmo domínio fonte (e.g. a VISÃO) pode ser utilizado para descrever vários domínios alvo (e.g. COMPREENDER, SABER, ANALISAR, JULGAR, etc.). Ao mesmo tempo, um domínio alvo (e.g. o TEMPO) pode ser descrito em termos de vários domínios fonte, nos quais cada um destaca uma caraterística e opaca as outras. Por exemplo, a expressão metafórica 'o tempo passa' deriva da metáfora conceptual o TEMPO É ESPAÇO/MOVIMENTO que enfatiza a ideia de mudança, mas oculta a noção de 
valor do tempo, o qual é enfatizado em outra metáfora conceptual como O TEMPO É DINHEIRO, que se manifesta através de muitas expressões metafóricas como 'investir o tempo livre' ou 'malgastar o tempo'.

(4) A unidirecionalidade é outro dos princípios importantes que regem a metáfora conceptual, ele refere à direção da projeção, a qual parte do domínio fonte ao domínio alvo, mas não de maneira contrária. Por exemplo, na metáfora conceptual o TEMPO É DINHEIRO, o tempo é definido em termos do dinheiro, mas o dinheiro não é definido em termos do tempo.

De acordo com a função, as metáforas são classificadas em estruturais, ontológicas e orientacionais (Lakoff e Johnson, 1980); porém, só as metáforas estruturais são relevantes para a nossa análise. As metáforas estruturais são aquelas que definem um campo semântico em termos de outro de modo sistemático. Assim, um campo como O TEMPO é difícil de ser explicado devido a que é abstrato e não se tem contato físico como no caso do DINHEIRO com o que de fato temos esse tipo de experiência. Portanto, a metáfora conceptual O TEMPO É DINHEIRO motiva expressões de vocabulário como 'perder', 'investir', 'dispor', 'custar', 'malgastar', etc. as quais constituem um modo sistemático de falar acerca do tempo.

A conceptualização do tempo em termos de dinheiro não se dá de maneira arbitrária. Na cultura ocidental, o tempo é algo valioso, um recurso limitado que se usa para cumprir tarefas e conseguir objetivos; desse modo, o conceito de trabalho está fortemente ligado ao conceito de tempo; por tal motivo, é costume pagar às pessoas por horas de trabalho, por semana ou por mês. Para a cultura ocidental, O TEMPO se manifesta de muitas maneiras: o custo das chamadas telefônicas em minutos, os salários por hora, os orçamentos anuais, os interesses bancários por mês, os estacionamentos e muitos outros serviços pagos por hora. Essa forma de pensar se manifesta na língua através de diversas expressões metafóricas.

QUADRO 1. Metáfora conceptual: TEMPO É DINHEIRO

\section{TEMPO É DINHEIRO}

Está perdendo seu tempo.

Se você for à fila preferencial vai poupar tempo.

Não tenho tempo.

Estou investindo muito tempo nesse projeto.

Preciso calcular meu tempo. 


\section{QUADRO 2. Metáfora conceptual: DISCUSSÃO É GUERRA}

\section{DISCUSSÃO É GUERRA}

Ela tem estratégias de convencimento.

As mulheres sempre ganham as discussões.

Eu me defendi, mas ele argumentou muito bem.

Ele começou me atacar com seus argumentos.

Sempre perco com ele.

Por outro lado, para esquematizar os processos que ocorrem nos ditados, é necessário recorrer à Gramática Cognitiva (GC) que propõe os conceitos de domínio cognitivo e domínio matriz.

O significado linguístico envolve tanto o conteúdo conceptual quanto o construto imposto para tal conteúdo. Na GC, o termo domínio é adoptado para se referir a esse conteúdo. Uma expressão ativa um conjunto de domínios cognitivos como base para a construção do seu significado (Langacker, 2007).

Existem concepções que podem incluir outras concepções ou podem ser de certa forma, reduzidas a noções mais fundamentais; assim, os domínios são divididos em básicos e não básicos (ou abstratos). Um domínio básico é um domínio cognitivamente irredutível, que não deriva nem pode ser analisável dentro de outras concepções; os mais recorrentes são ESPAÇO, TEMPO, TEMPERATURA, PALADAR, AROMA, etc. Os domínios básicos não são nem conceptos, nem conceptualizações, eles derivam diretamente da experiência. No entanto, os domínios que são conceptualizados a partir dos domínios básicos são os domínios abstratos, aqueles derivados de sensações sensoriais, emotivas e experiências motrizes (e.g. SENSAÇÃO DE MEDO), bem como produtos de operações intelectuais (e.g. JUSTIÇA), concepções manifestadas conscientemente (e.g. A IMAGEM DE UM CÍRCULO) e cenários elaborados (e.g. os PASSOS DE UMA RECEITA). Os domínios abstratos não são fixos nem reconhecidos convencionalmente, eles podem variar segundo o contexto situacional.

Uma expressão geralmente evoca mais de um domínio cognitivo. O conjunto de domínios evocados por uma expressão é chamado de domínio matriz, portanto, o domínio matriz de uma expressão pode ser complexo e se faz necessário não só listar os domínios cognitivos evocados por ela, mas também a relação que existe entre tais 
domínios e como eles são mentalmente acessados. O domínio matriz pode ser muito detalhado ou superficial, dependendo do propósito da análise.

\section{O CORPUS: O MATERIAL LINGUÍSTICO}

As perguntas de pesquisa propostas apontam para uma análise das metáforas como processos semânticos que mostram como nosso esquema cognitivo mental manifesta-se através da língua, especialmente através dos ditados populares. Para tal objetivo, nesse trabalho foram coletados dez ditados populares obtidos de manuais de ensino de espanhol $^{1}$; tais ditados estão dentro do campo semântico dos animais.

[1] A cada puerco le llega su San Martín.

[2] Aunque la mona se vista de seda, mona se queda.

[3] Cuando el gato está fuera, los ratones se divierten.

[4] Gallina vieja da buen caldo.

[5] La cabra tira al monte.

[6] La zorra mudará los dientes, mas no las mientes.

[7] No es tan bravo, ofiero, el león como lo pintan.

[8] Perro que ladra no muerde.

[9] Quien con lobos anda, a aullar aprende.

[10] El hijo de la gata, ratones mata.

\section{A METÁFORA ESTRUTURAL: AS PESSOAS SÃO ANIMAIS}

As metáforas são projeções de um domínio fonte sobre um domínio alvo. O objetivo desse processo semântico-cognitivo é facilitar a compreensão de um conceito através de analogias. (Cuenca e Hilferty, 1999).

No corpus, há dez ditados motivados pela mesma metáfora conceptual AS PESSOAS SÃO ANIMAIS, esta metáfora permite explicar o comportamento e aparência das pessoas através de comparações com o comportamento e aparência, reais ou percebidos, dos animais.

\footnotetext{
${ }^{1}$ Foram revisados oito manuais de ensino de espanhol produzidos em América Latina. Os títulos dos manuais são (1) Curso de español ECELA Avanzado superior, (2) Veintiún temas de conversación superior, (3) ECELA curso de español C1 Los problemas en América Latina, (4) ECELA curso de español C1 Las relaciones, (5) ECELA curso de español C2 La vida en América Latina, (6) Curso de español Nivel Superior A Hispana, (7) Curso de español Nivel Superior B Hispana e (8) Curso de español Nivel Superior C Hispana.
} 
O uso de animais como porco, macaca, gato, rato, galinha, cabra, raposa, leão, cachorro, lobo e gata não é arbitrário para a estruturação dos ditados; se em lugar desses animais fossem colocados animais como crocodilo, elefante, girafa, urso ou outros, os ditados não teriam o mesmo efeito. Isso ocorre porque a metáfora conceptual As PESSOAS SÃO ANIMAIS motiva sub-metáforas, nas quais são associados animais específicos a cada tipo de pessoa.

Em cada cultura, os animais possuem propriedades específicas que destacam e que os caracterizam de alguma maneira. Assim, quando é usado o nome de um animal para descrever uma pessoa é para enfatizar certas qualidades. Por exemplo, na cultura hispânica, quando se chama alguém de tortuga (tartaruga) quer-se destacar a característica de lentidão da pessoa, mas ignoram-se outros atributos como comer alface, ser de cor verde ou ter uma carapaça enorme. Essa é uma das funções dos ditados, ajudar a compreender um conceito em termos de outro mais dinâmico e que seja fácil de fixar na mente.

Assim, na cultura hispânica, a metáfora conceptual AS PESSOAS SÃO ANIMAIS está presente de muitas formas. Pelos atributos físicos: Os gordos são ballenas, vacas, cerdos (baleias, vacas, cerdos), os que têm dentes grandes são conejos (coelhos); pelo tipo de comportamento: os homossexuais são patos, chivos, cabras (patos, bodes, cabras), os curiosos são sapos (sapos), os bobos são pavos, burros (perus, burros), os casais apaixonados são tórtolos (pombas-rolas), os trabalhadores são hormigas (formigas), os corruptos são ratas (ratos), os que dormem muito são lirones (arganazes), os vigorosos são tigres (tigres) e assim por diante.

Para a análise do corpus, identificar-se-á o termo metafórico em negrito e far-seá a gráfica do domínio matriz para tal conceito; logo depois sinalizar-se-á o domínio cognitivo projetado (sombreado) no domínio alvo e quais são os domínios cognitivos que são irrelevantes no mapeamento (os não sombreados) e, portanto, não são projetados.

[1] A cada puerco le llega su San Martín. 
FIGURA 1. Domínio matriz de puerco

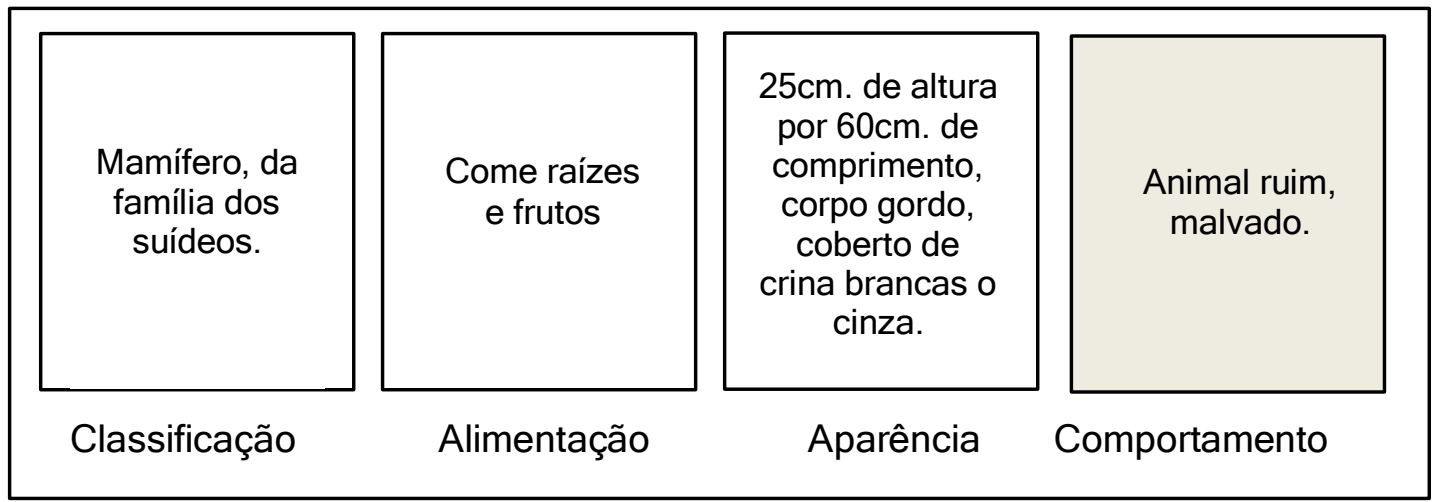

Os quatro domínios cognitivos da FIGURA 1 (classificação, alimentação, aparência e comportamento) permitem delimitar o conceito de puerco (porco), porém, para a construção da metáfora o único domínio cognitivo relevante é o comportamento; portanto, a classificação, a alimentação e a aparência resultam irrelevantes para o mapeamento.

FIGURA 1.1. Metáfora conceptual: AS PESSOAS SÃO ANIMAIS

Domínio fonte: ANIMAIS

Domínio alvo: PESSOAS

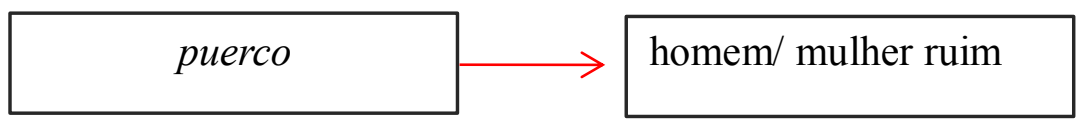

O comportamento ruim do porco tem origem na cultura espanhola. Na Espanha, existe uma festa tradicional chamada 'a matança do porco' que é realizada antes do inverno e é usada como ponto de referência para a festa de San Martín de Tours (11 de novembro). As famílias reúnem-se para testemunhar a matança do porco que é posteriormente queimado; depois os membros da família ajudam a esquartejar o animal e o separam em partes para ser conservado para todo o inverno.

Devido a essa festa, se iniciou o ditado A cada puerco le llega su San Martín. Nesse ditado se compara o porco com uma pessoa ruim e essa matança -representada pela festa de San Martín- seria o castigo que todos recebem pelo seu mau comportamento.

[2] Aunque la mona se vista de seda, mona se queda. 
FIGURA 2. Domínio matriz de mona

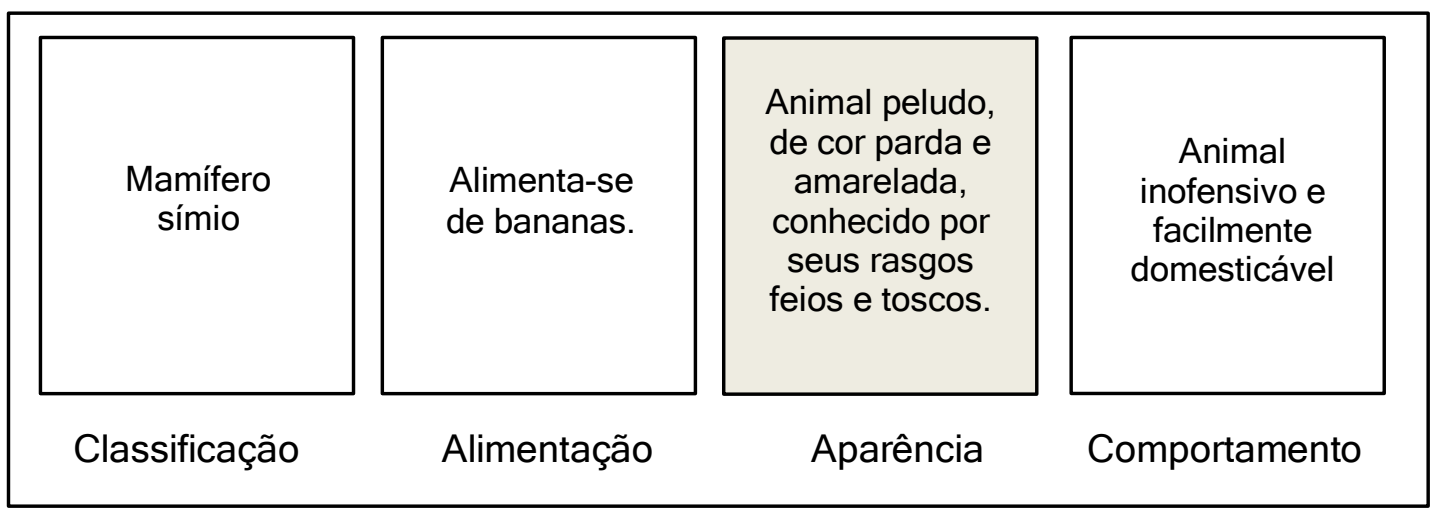

Nesse ditado, a propriedade do animal que é mais relevante não é o comportamento, como no caso do porco, mas sim a aparência. As caraterísticas de ser mamífero, comer bananas, ser facilmente domesticável permanecem ocultos e não são projetados no domínio alvo.

FIGURA 2.1. Metáfora conceptual: AS PESSOAS SÃO ANIMAIS

Domínio fonte: ANIMAIS

Domínio alvo: PESSOAS

\begin{tabular}{c|c|} 
mona & mulher feia \\
\hline
\end{tabular}

A mona (macaca) é considerada um animal muito feio na cultura hispânica e nesse ditado, faz-se referência ao fato de que nada pode mudar a feiura de uma mulher, embora ela use roupas ou joias muito finas e elegantes, ela continuará sendo feia.

[3] Cuando el gato está fuera, los ratones se divierten.

FiguRA 3. Domínio matriz de gato

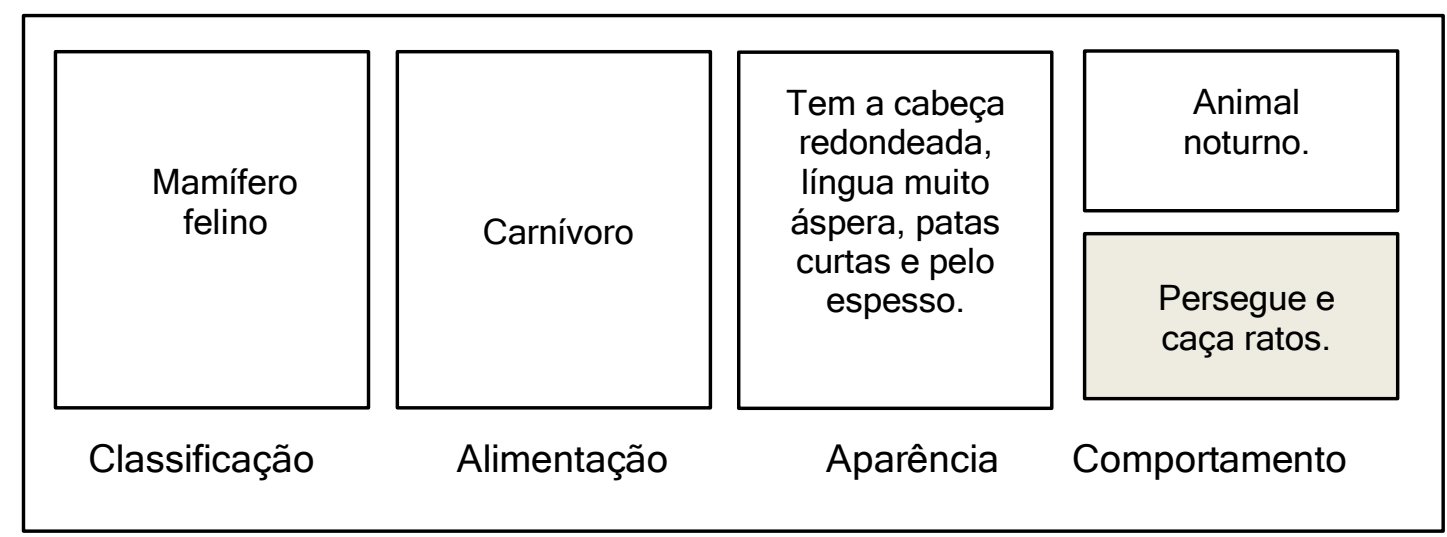


FiguRA 3.1. Domínio matriz de ratón

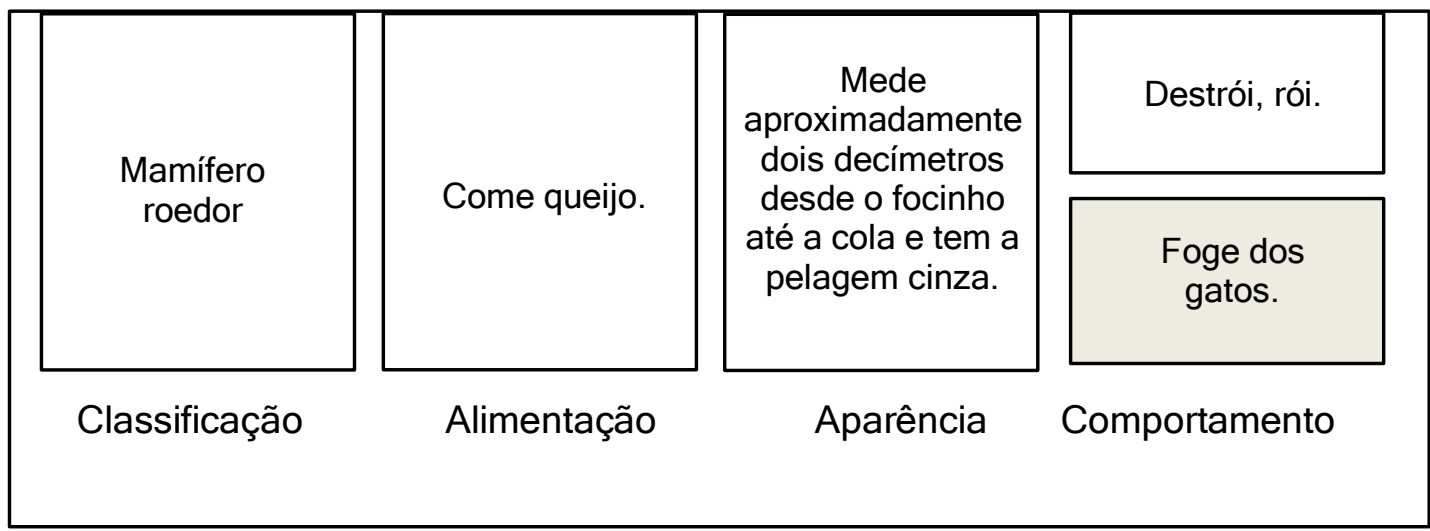

Nesse caso, a metáfora apresenta a relação analógica que existe entre os gatos (gatos) e os ratones (ratos) por um lado e os chefes e seus subordinados pelo outro. Assim, cada um dos domínios cognitivos de 'gato' seria irrelevante se não se considera, ao mesmo tempo, a relação existente com o domínio cognitivo do comportamento do 'rato'.

FIGURA 3.2. Metáfora conceptual: AS PESSOAS SÃO ANIMAIS

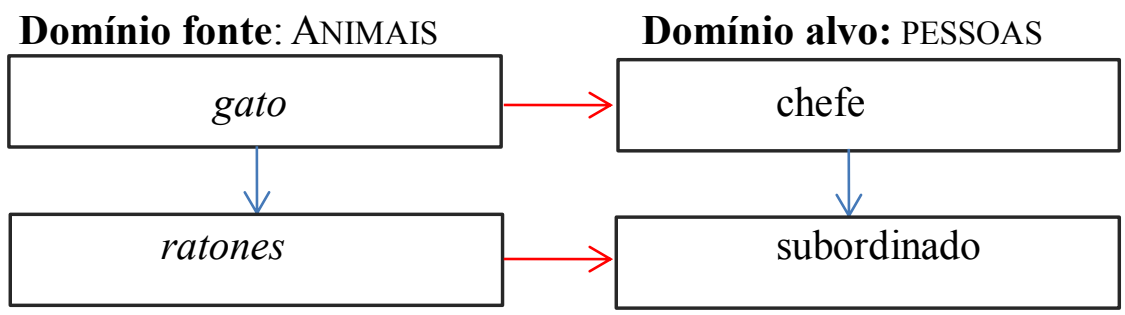

No ditado [3], define-se 'gato' segundo a hierarquia com relação aos ratos, e faz-se uma equivalência com um chefe com relação aos seus empregados ou do cabeça da família com relação aos seus filhos; embora não aconteça em todos os casos, existe a ideia de que os ratos tem medo dos gatos, porque o gato tem fama de caçador de ratos e em muitas situações só o cheiro de gato espanta e afasta os ratos de um lugar e os obriga a se esconder; portanto, quando o gato está longe ou não está, os ratos aproveitam para sair do seu refúgio.

Analogicamente, na cultura hispânica (provavelmente, ocidental) quando os empregados estão sob a vigilância de um superior, seu comportamento é similar: evitam o que não está permitido como falar pelo telefone, bater papo com os amigos, comer, etc., porém, quando o chefe não está, eles aproveitam para fazer tudo com liberdade. 
[4] Gallina vieja da buen caldo.

FiguRA 4. Domínio matriz de gallina

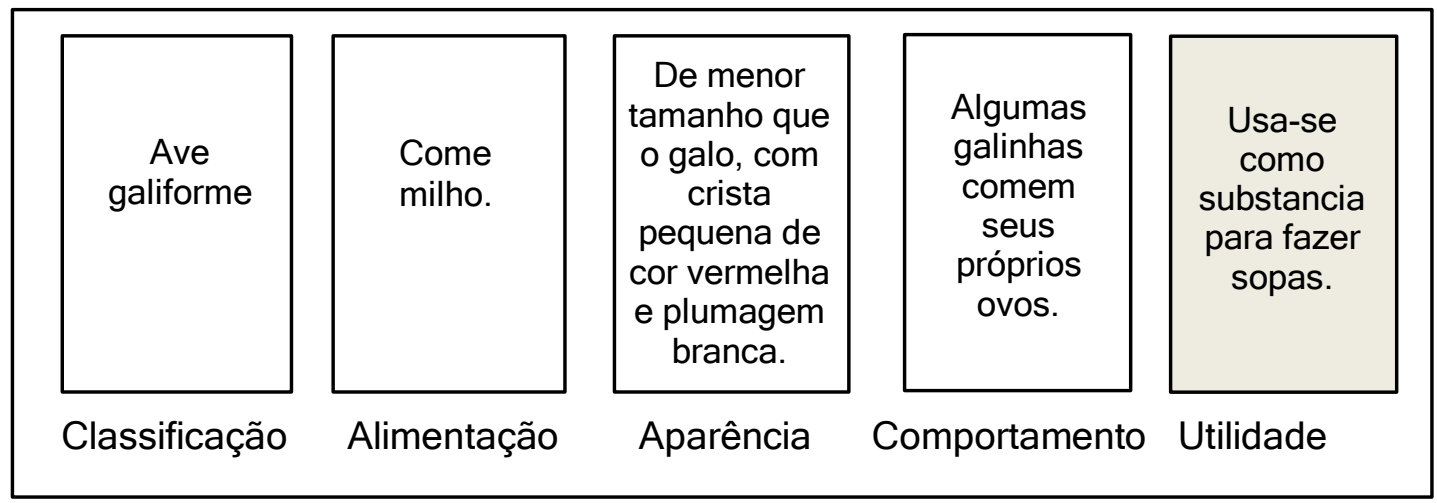

No caso do ditado [4], o domínio cognitivo que resulta relevante é a utilidade. As galinhas normais produzem uma sopa pouco substanciosa; enquanto que as gallinas (galinhas) velhas produzem uma sopa muito substanciosa. Essa caraterística da galinha é a que se projeta para destacar a capacidade das mulheres velhas de agir melhor e com maior reflexão.

FIGURA 4.1. Metáfora conceptual: AS PESSOAS SÃO ANIMAIS

Domínio fonte: ANIMAIS

Domínio alvo: PESSOAS

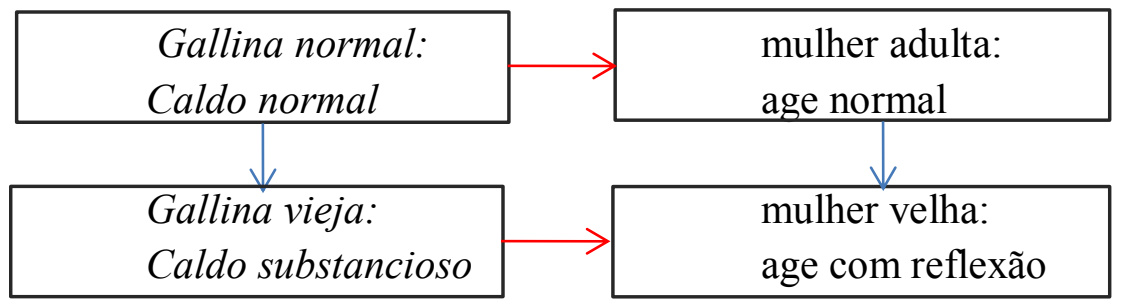

No mundo da gastronomia, acredita-se que a gallina vieja (galinha velha) é a mais substanciosa e, portanto, ao preparar uma sopa com uma galinha velha, a sopa fica mais saborosa. Esta situação compara-se analogicamente com o fato de que as mulheres mais velhas, pelo fato de terem vivido mais anos e terem mais experiências, acumulam muita sabedoria e podem oferecer e ensinar mais do que uma mulher nova e inexperiente que não tem vivências suficientes.

Desse modo, a propriedade que é destacada e projetada às pessoas (no caso, mulheres) é a idade, a qual se encaixa numa relação diretamente proporcional: 'mais idade, mais substância' no caso das galinhas; e 'mais idade, mais experiência' no caso das mulheres. 
Este ditado é utilizado com maior frequência nos relacionamentos onde a mulher é mais velha do que o homem e se justifica dizendo que gallina vieja da buen caldo; isto é, a mulher adulta sabe muito mais e pode oferecer mais num relacionamento do que uma garota.

\section{[5] La cabra tira al monte.}

Figura 5. Domínio matriz de cabra

\begin{tabular}{|l|l|c|c|}
\hline \begin{tabular}{|l|l|}
\hline $\begin{array}{c}\text { Mamífero } \\
\text { ruminante } \\
\text { doméstico. }\end{array}$ & Herbívoro um \\
metro e meio \\
de altura, é \\
leve, esbelto, \\
pelo curto, \\
áspero e \\
meio \\
vermelho. \\
Classificação
\end{tabular} & $\begin{array}{c}\text { Gosta de } \\
\text { pastar e ficar } \\
\text { no monte. }\end{array}$ \\
Alimentação & Aparência Comportamento \\
\hline
\end{tabular}

A caraterística relevante da cabra (cabra) é a sua preferência por pastar no monte. Essa propriedade é projetada no domínio das PESSOAS, assinalando aquelas pessoas que preferem sempre ficar no seu lugar de origem do que em qualquer outro.

FIGURA 5.1. Metáfora conceptual: AS PESSOAS SÃO ANIMAIS

Domínio fonte: ANIMAIS Domínio alvo: PESSOAS

\begin{tabular}{|l|l|}
\hline cabra & $\rightarrow \begin{array}{l}\text { homem/mulher arraigado } \\
\text { ao lugar de origem }\end{array}$ \\
\hline
\end{tabular}

Segundo veterinários especialistas em caprino, as cabras são animais astutos e muito inteligentes, elas preferem ir ao monte para pastar; assim, quando são levadas a outro lugar ao que não estão acostumadas, sempre tentam fugir e voltar ao monte.

Tal situação é comparada à atividade humana, no caso de algumas pessoas que migram de cidade ou país, porém mantêm seus costumes muito arraigados ou, mesmo se não se acostumam, voltam ao lugar de origem.

[6] La zorra mudará los dientes, mas no las mientes. 
FIGURA 6. Domínio matriz de zorra

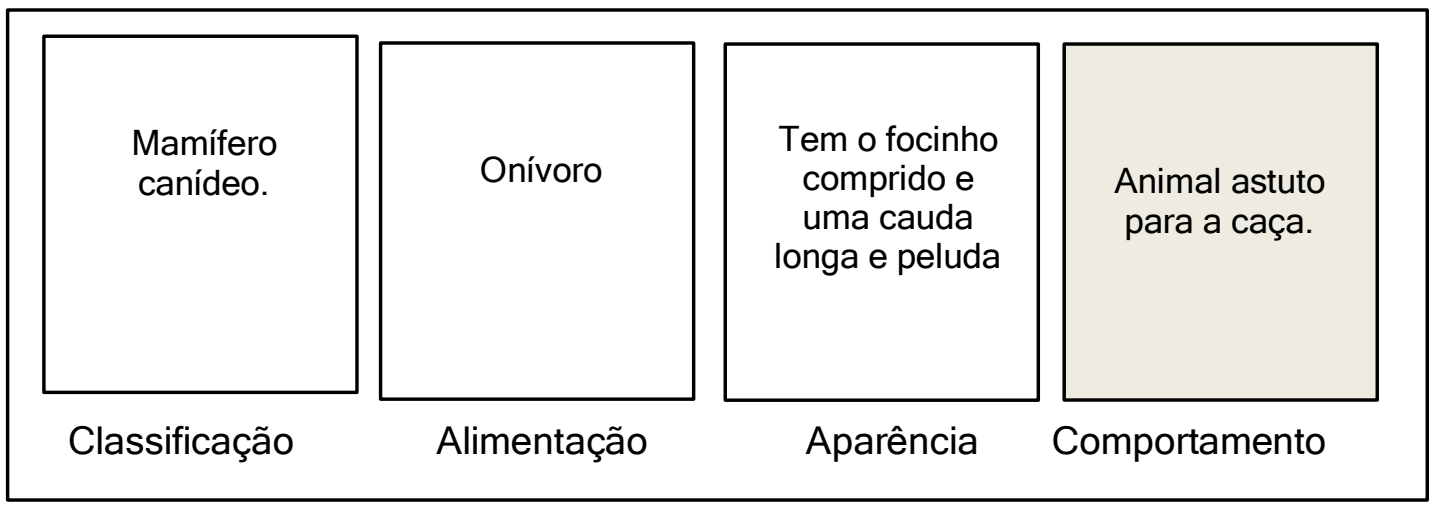

Uma das caraterísticas mais salientes da zorra (raposa) é a astucia dela para caçar. Esta capacidade é a que se projeta no domínio das PESSOAS; especificamente, mulheres.

FIGURA 6.1. Metáfora conceptual: AS PESSOAS SÃO ANIMAIS

Domínio fonte: ANIMAIS

Domínio alvo: PESSOAS

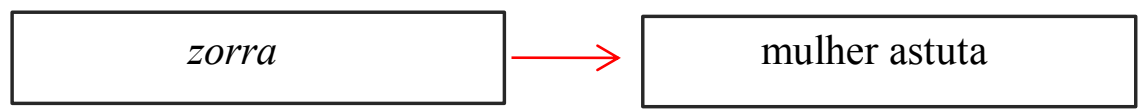

O ditado [6] faz referência às mulheres astutas que, ao longo da sua vida, podem mudar muitas coisas por causa da idade: o cabelo, os dentes, o peso, etc., porém nunca as mientes (palavra espanhola antiga que significa 'ideias, pensamentos'); então, embora existam mudanças superficiais, a astúcia e as manhas que elas têm não mudarão.

[7] No es tan bravo, ofiero, el león como lo pintan.

FiguRA 7. Domínio matriz de león

\begin{tabular}{|c|c|c|c|}
\hline $\begin{array}{l}\text { Mamífero } \\
\text { felídeo. }\end{array}$ & Carnívoro & $\begin{array}{c}\text { Tem a cabeça } \\
\text { grande e melena } \\
\text { abundante. Unhas } \\
\text { e dentes muito } \\
\text { fortes. Pelagem } \\
\text { amarelada e } \\
\text { tamanho } \\
\text { imponente. }\end{array}$ & $\begin{array}{l}\text { Animal } \\
\text { caçador e } \\
\text { muito veloz. }\end{array}$ \\
\hline Classificação & Alimentação & Aparência & Comportamento \\
\hline
\end{tabular}


O león (leão), cuja aparência faz pensar que é um animal muito feroz, todopoderoso e invencível, é conhecido por ser forte; porém, este ditado indica que ele não seria tão forte quanto sua aparência mostra. Esta mesma situação compara-se analogicamente com os homens que não por serem musculosos, masculinos $\mathrm{e}$ imponentes fisicamente, são realmente fortes e corajosos.

FIGURA 7.1. Metáfora conceptual: AS PESSOAS SÃO ANIMAIS

Domínio fonte: ANIMAIS Domínio alvo: PESSOAS

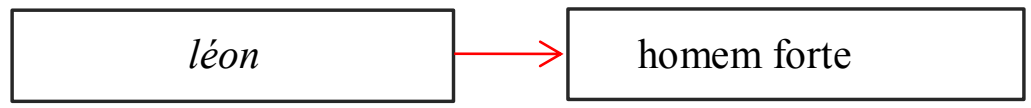

[8] Perro que ladra no muerde.

FiguRA 8. Domínio matriz de perro

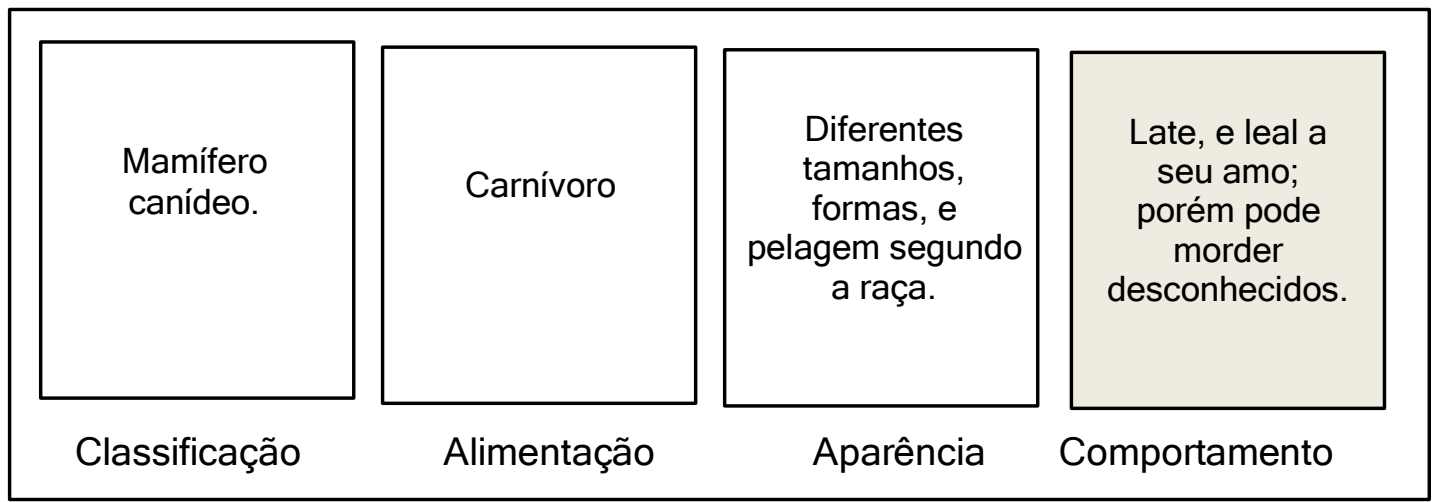

Nesse caso a propriedade projetada seria o comportamento do perro (cachorro) quando late para as pessoas, porém não morde, o qual é similar ao comportamento de muitas pessoas que ameaçam muito, porém na hora não fazem nada.

FIGURA 8.1. Metáfora conceptual: AS PESSOAS SÃO ANIMAIS

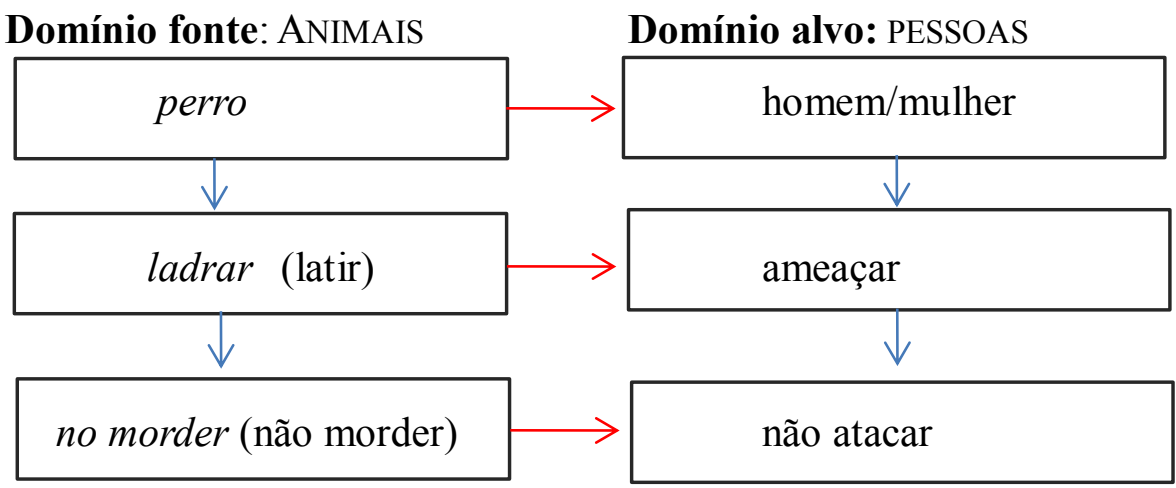


É bastante comum que, na vida real, as pessoas que mais falam, que mais ameaçam e que tentam criar medo ou amedrontar os seus oponentes mediante estratégias verbais sejam as pessoas que, no momento indicado, menos reagem.

[9] Quien con lobos anda, a aullar aprende.

\section{FIGURA 9. Domínio matriz de lobo}

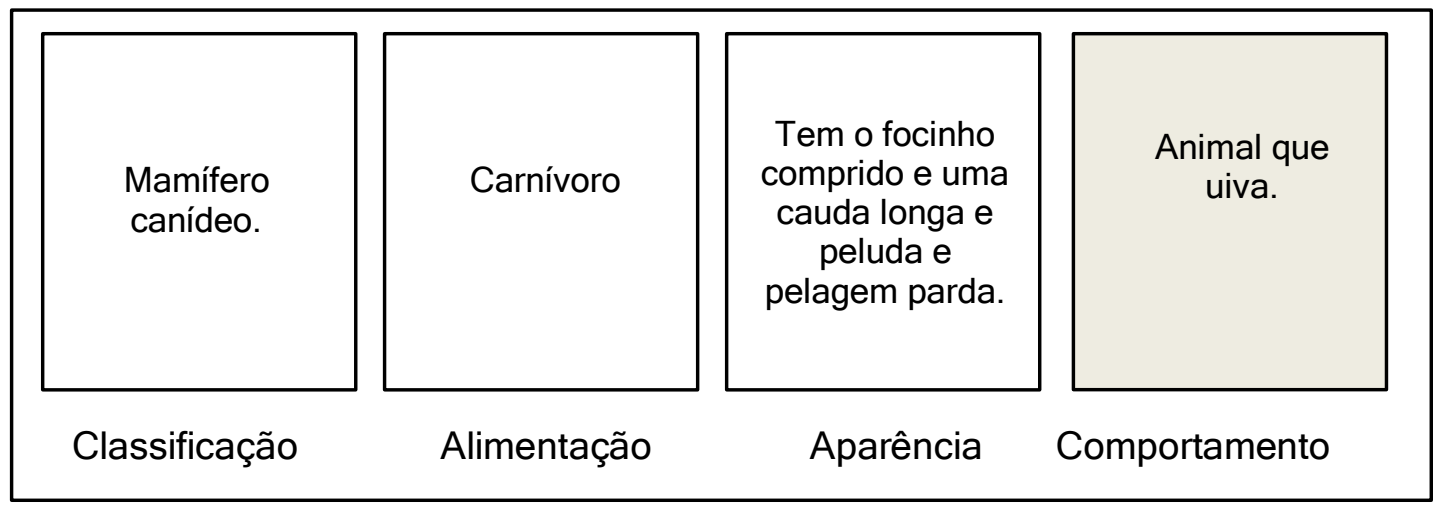

A propriedade projetada é o comportamento, especificamente a capacidade que tem os lobos de uivar; então, quem se junta com os lobos aprende as mesmas manhas que eles; em analogia com as pessoas, quem se junta com pessoas que têm manhas, aprenderá as mesmas manhas.

FIGURA 9.1. Metáfora conceptual: AS PESSOAS SÃO ANIMAIS Domínio fonte: ANIMAIS Domínio alvo: PESSOAS

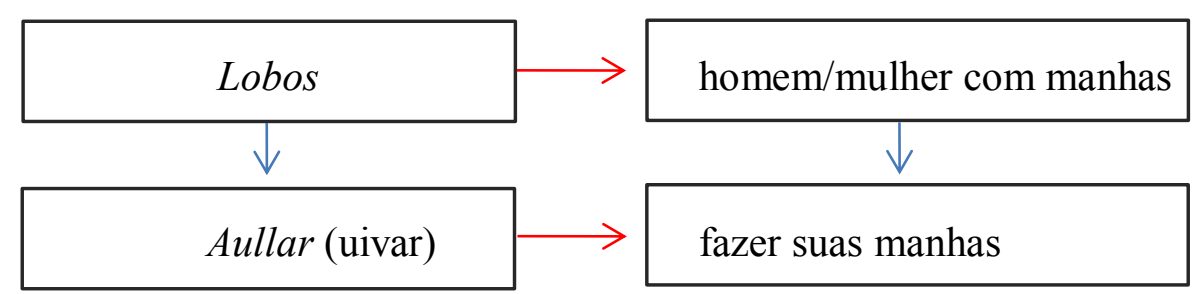

Os lobos são conhecidos por serem animais muito astutos e aguçados para a caça. Esta característica é projetada ao domínio das pessoas que têm manha para realizar algumas atividades, geralmente negativas, e a pessoa que se junta ao grupo adquirirá as mesmas manhas. Desse modo, se uma pessoa se une a um grupo de delinquentes, ela 
aprenderá a delinquir, se se une a um grupo de assaltantes, aprenderá a assaltar, e assim por diante.

[10] El hijo de la gata, ratones mata.

Figura 10. Domínio matriz de gato

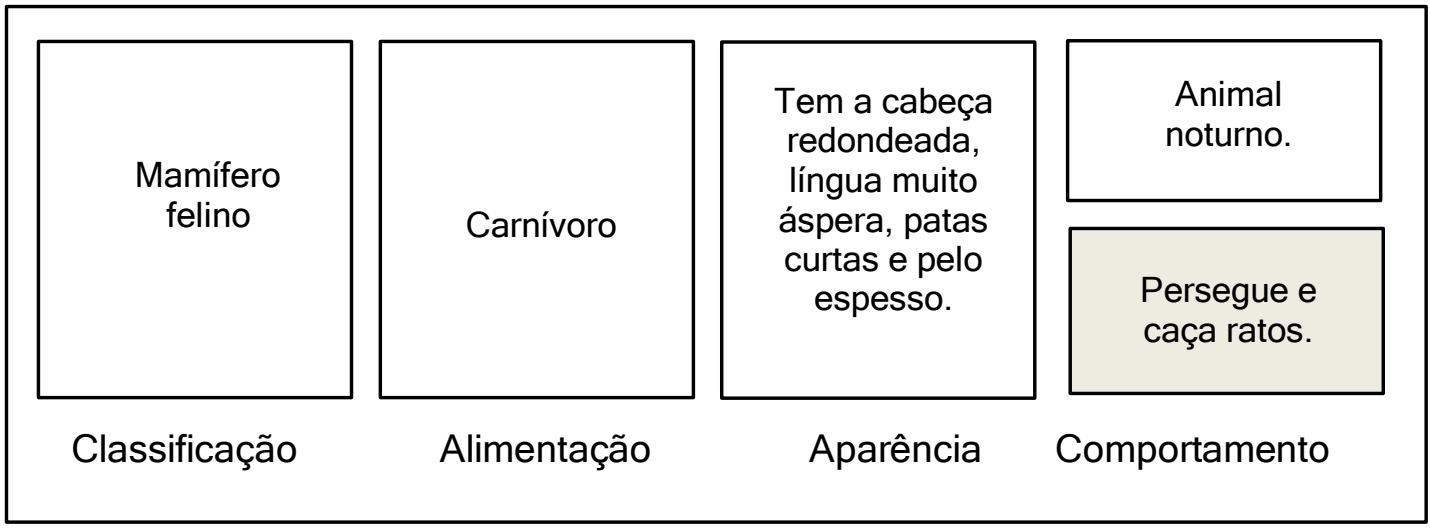

O ditado [10] indica a poderosa influência que têm os pais sob os filhos na sua natureza genética. Neste caso, o fato de caçar ratos (ou matá-los) é uma propriedade que caracteriza os gatos; portanto, é o primeiro que será herdado geneticamente pelos filhotes. Do mesmo modo, os filhos herdam dos pais suas principais habilidades/atitudes.

FIGURA 10.1. Metáfora conceptual: AS PESSOAS SÃO ANIMAIS

Domínio fonte: ANIMAIS

\begin{tabular}{|c|c|}
\hline A gata caça ratos. & Os pais tem costumes/habilidades. \\
\hline$\downarrow$ & $\downarrow$ \\
\hline Seus filhotes caçam ratos. & $\begin{array}{l}\text { Os filhos têm os mesmos } \\
\text { costumes/habilidades. }\end{array}$ \\
\hline
\end{tabular}

\section{CONSIDERAÇÕES FINAIS}

Uma das caraterísticas dos ditados é transmitir uma mensagem produto da experiência e sabedoria popular com objetivo de que esse conhecimento seja fixado na mente dos falantes. Para isso, os ditados devem ser dinâmicos, portanto, o processo semântico-cognitivo mais recorrente é a metáfora, a qual não se apresenta como um recurso estilístico, mas como um recurso que permite facilitar a compreensão. Mediante 
este processo se destacam certos domínios cognitivos de um elemento; enquanto que outros domínios são opacados por resultarem irrelevantes no mapeamento. Desse modo, os ditados podem captar a atenção e fixar a mensagem na mente do ouvinte. Por não serem diretos e incluir informação cultural, os processos semântico-cognitivos presentes nos ditados podem dificultar a interpretação por parte dos aprendizes da língua, por isso se faz necessária uma análise pertinente.

A metáfora conceptual analisada AS PESSOAS SÃO ANIMAIS pode estar presente em mais de uma cultura, porém o modo em que cada animal é percebido, as características que são associadas a cada animal variam radicalmente de cultura a cultura, motivando diferentes expressões metafóricas em cada língua. Desse modo, os ditados populares são considerados estruturas muito ricas em informação linguística e cultural.

\section{REFERÊNCIAS}

ALMELA, R.; SEVILLA, J. Paremiología contrastiva: propuesta de análisis linguístico. Revista de Investigación Lingüística, pp. 7-47, 2000.

ALONSO, M. Ciencia del lenguaje y arte del estilo. Madrid: Aguilar, 1978.

CASARES, J. Introducción a la lexicografía moderna. Madrid: C.S.I.C., 1992.

CORPAS, G. Manual de fraseología española. Madrid: Editorial Gredos, 1996.

CUENCA, M.; HILFERTY, J. Introducción a la lingüística cognitiva. Barcelona: Editorial Ariel, 1999.

LAKOFF, G.; JOHNSON, M. Metáforas de la vida cotidiana. Madrid: Ediciones Cátedra, 1980.

LANGACKER, R. Cognitive Grammar. Oxford: Oxford University Press, 2007.

MARTÍNEZ, L. Refranero ideológico español. Madrid: Editorial Hernando, 1989.

PENADÉS, I. El valor discursivo en los refranes. ELUA, pp. 287-304, 2006.

PENADÉS, I. La fraseología y su objeto de estúdio. Linred, pp. 1- 17, 2012.

PÉREZ, H. Refrán viejo nunca miente. Zamora: El Colegio de Michoacán, 1993.

PÉREZ, H. El hablar lapidario. Ensayo de paremiología mexicana. Zamora: El Colegio de Michoacán, 1997. 
SEVILLA, J. Hacia una aproximación conceptual de las paremias francesas y españolas. Madrid: Editorial complutense, 1988.

SEVILLA, J. La fraseología y la paremiología en los últimos decênios. Linred, pp. 129, 2012.

ZULUAGA, A. Introducción a las expresiones fijas. Frankfurt: Verlag Peter D. Lang, 1980.

\begin{abstract}
AAUTORA
Laura Pissani é mestranda do Programa de Pós-Graduação em Estudos da Linguagem da Pontifícia Universidade Católica de Rio do Janeiro (PUC-Rio, Brasil) na área de linguagem e cognição. Graduada em Linguística pela Universidade Nacional Mayor de San Marcos (UNMSM, Peru) e especializada em Linguística Cognitiva e Fraseologia. E-mail: laurapissani@gmail.com
\end{abstract}

